'||||||||||||||||||||||||||||||||||||||||||||||||||||||||||.

\section{In Motion}

narshate

Things are moving and in all directions, both good and bad, if we're allowed to say that. A Swedish vehicle manufacturer, which was one of the pioneers of the move away from developing new combustion engines, has presented its latest development: a Miller-cycle engine for use in mild hybrids. I see that as a clear statement of the company's position and a very pleasing one. By contrast, the UK government is banning the sale of new gasoline and diesel cars from 2030, five years earlier than planned. This is an extremely shortsighted move, particularly because none of the British manufacturers is yet producing the necessary volume of electrified cars, never mind BEVs. And, of course, the government then immediately back-pedaled and explained that the sales ban applies only to vehicles powered solely by a combustion engine. Hybrids can still be sold up to 2035 .

In the meantime, manufacturers of heavy-duty engines are stepping up to the plate. The most recent research projects and developments that will help the much-criticized shipping industry to become more environmentally friendly were presented at the MTZ Heavy-Duty Engines conference. A number of different approaches, including the use of largely synthetic alternative fuels and fuel blends, which can help to reduce the pollution and greenhouse gas emissions of the existing fleet, were the subject of intense discussion. Hydrogen and liquefied gases, with LNG leading the way, are being evaluated for new applications despite the costly cryogenic tanks and pipes needed to store these very low-temperature fuels.
It is clear that a rethink of our mobility systems is needed and also that we cannot function without electrification. How radical this rethink is will depend on each individual country. The German approach has been clearly laid out and, as you might expect, it involves hightech solutions. For example, the Chinese facility for vehicle batteries in the Saarland region. The location appears to be a good choice because the automotive industry and its suppliers are the largest employers in the region, ahead of the steel industry. From a technological perspective, the new factory also represents a step in the right direction, because the batteries will be manufactured without the use of cobalt.

I hope you enjoy this issue of MTZ.

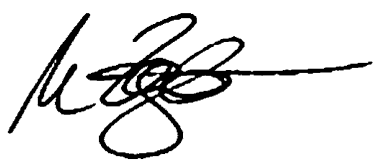

Marc Ziegler

Deputy Editor in Chief

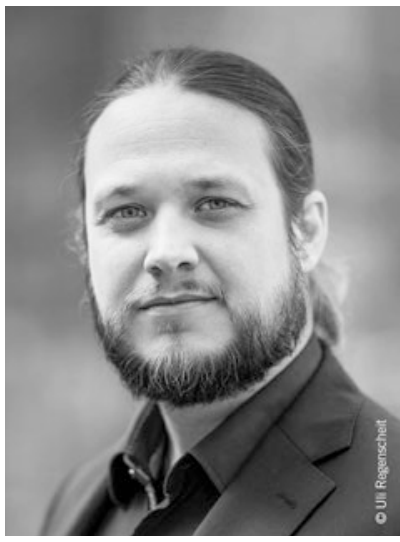
company SVolt is building a production

\section{visions DEVELOPMENT. MOBILITY.}

The world of mobility is changing. The challenge facing automotive developers is to acquire the knowledge they will need tomorrow without losing sight of future technologies. The complexity of the mobility transformation process calls for groundbreaking solutions. ATZelectronics provides the latest information from across the entire spectrum of automotive electronics. Take advantage of the interactive e-magazine and benefit from the extensive information in our unique online archive, which gives you the option of downloading PDF files.

\section{$A T z$ electronics}

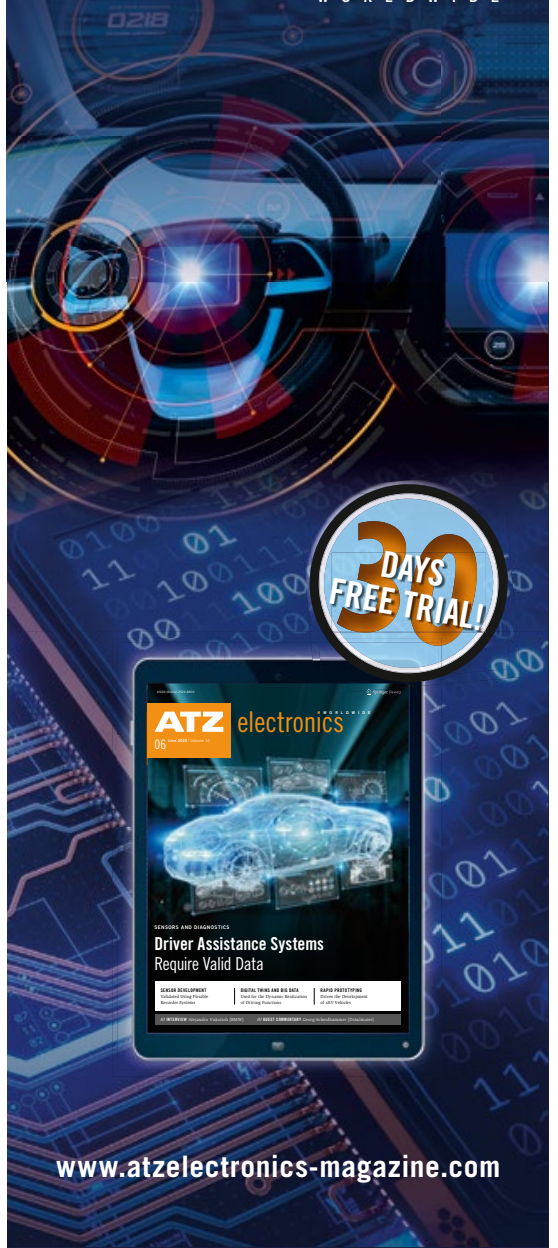

